\title{
Surgical technique of visceral segmental serosectomy for advanced ovarian cancer
}

\author{
Soo Jin Park, Hee Seung Kim \\ Department of Obstetrics and Gynecology, Seoul National University College of Medicine, Seoul, Korea \\ Contributions: (I) Conception and design: All Authors; (II) Administrative support: HS Kim; (III) Provision of study materials or patients: HS Kim; \\ (IV) Collection and assembly of data: All Authors; (V) Data analysis and interpretation: All Authors; (VI) Manuscript writing: All authors; (VII) Final \\ approval of manuscript: All authors. \\ Correspondence to: Hee Seung Kim, MD, PhD. Department of Obstetrics and Gynecology, Seoul National University College of Medicine, 101 \\ Daehak-Ro Jongno-Gu, Seoul 110-744, Korea. Email: bboddi0311@gmail.com.
}

\begin{abstract}
Tumors infiltrating the recto-sigmoid colon are commonly detected during cytoreductive surgery in patients with advanced ovarian cancer. Although radical excision using low anterior resection (LAR) is traditionally needed for optimal cytoreduction in the patients, LAR commonly decrease postoperative quality of life by changes of bowel habit. Since there is increasing evidence that conservative ablation of tumors on the recto-sigmoid colon may be safe and effective like LAR without compromising quality of life, we developed the surgical technique of visceral segmental serosectomy (VSS) as one of conservative ablation methods for complete resection of serosal implants on the recto-sigmoid colon and scrupulous restoration of extended serosal defect after resection. Thus, this video will show the step by step procedure of VSS during cytoreductive surgery for advanced ovarian cancer.
\end{abstract}

Keywords: Advanced ovarian cancer; recto-sigmoid colon; visceral segmental serosectomy (VSS)

Submitted Jan 02, 2020. Accepted for publication Apr 24, 2020.

doi: $10.21037 /$ gs-2019-ursoc-03

View this article at: http://dx.doi.org/10.21037/gs-2019-ursoc-03

\section{Introduction}

The recto-sigmoid colon is the most common viscera infiltrated by tumors in advanced ovarian cancer (1). Two surgical procedures can be considered to remove tumors on the recto-sigmoid colon as follows; low anterior resection (LAR) and conservative ablation such as Douglas peritonectomy (2). Although LAR is known to be the definite method for radical excision of tumors infiltrated to the recto-sigmoid colon in patients with advanced ovarian cancer, it has two limitations as follows. First, about $40 \%$ of the patients who underwent LAR complain frequency or urgency of stools or stool incontinence, which leads to poor quality of life after surgery (3). Moreover, anastomotic site leakage can develop in about $5 \%$ of the patients after LAR despite prophylactic ileostomy (1), which is known to be related with poor prognosis $(4,5)$. On the other hand, conservative ablation can allow microscopic or infiltrative residual tumors after surgery affecting poor prognosis despite preservation of large bowel function (6). However, no gross residual tumor is preferred as the criteria of optimal cytoreduction instead of R0 resection because of too much tumor burdens in advanced ovarian cancer $(7,8)$, and recent studies have shown that conservative ablation may be safe and effective like LAR in the patients $(2,9)$.

Thus, we developed the surgical technique of visceral segmental serosectomy (VSS) as one of conservative ablation methods for complete resection of serosal implants on the recto-sigmoid colon and scrupulous restoration of extended serosal defect after resection, and this video will show the step by step procedure of VSS during cytoreductive surgery for advanced ovarian cancer (Video 1).

\section{Operative techniques}

\section{Patient selection}

We included patients with stage IIB to IVB ovarian, 
fallopian, and primary peritoneal cancer who need resection of tumors involving the recto-sigmoid colon for maximal cytoreduction. For the patients, we preferred VSS when the length of the recto-sigmoid colon where tumors invaded was $18 \mathrm{~cm}$ or less without multiple mucosal invasion of tumors. However, we changed VSS into LAR if the length of the recto-sigmoid colon where tumors invaded was more than $18 \mathrm{~cm}$ or multiple mucosal invasion was suspicious because of the risk of leakage at the primary repair site due to excessive tension or weakness by multiple or large defect of mucosa layer.

\section{Operative procedure}

Under general anesthesia, the patient took the lithotomy position. After the midline incision is made from the xiphoid process to pubis, the probability of resection of all visible tumors was evaluated in the first time, and then we mobilized the colon and both ureters for preventing iatrogenic injury. Then, we divided the plane between the uterus and recto-sigmoid colon, and mobilized the recto-sigmoid colon sufficiently from the pelvic cavity by developing the rectovaginal space. After elevating the rectosigmoid colon, the inferior hypogastric nerve was identified and secured during this procedure.

Next, we performed mesorectal excision for removing seeding nodules on bilateral sides of the rectum. After completion of mesorectal excision, the length of the rectosigmoid colon where tumors invaded was evaluated, and we did VSS if it was $18 \mathrm{~cm}$ or less without multiple mucosal invasion of tumors. If the tumor was infiltrated deeper than the mucosal layer or extended more than $18 \mathrm{~cm}$ of the recto-sigmoid colon, it was determined that it was not suitable for VSS. In that case, we performed LAR for excision of the tumor located in the recto-sigmoid colon.

After complete resection of serosal implants on the recto-sigmoid colon, tagging sutures were done at the left and right mediolateral edges of the resection area, and then we performed the tagging suture at the right anterolateral edge. Thereafter, we repaired the right lateral serosa, and then the tagging suture was done at the left anterolateral edge. After we repaired the left lateral serosa, we finally repaired the anterior serosa, which made the recto-sigmoid colon a U-shaped loop. Since air leakage at the anastomotic site on the bubble leakage test is known to increase the risk of postoperative colorectal anastomic leakage (10), we performed the bubble leakage test at the repair site of VSS.

\section{Comments}

VSS may be a feasible and easy technique for conservative ablation of tumors infiltrated to the recto-sigmoid colon with complete resection of serosa implants.

\section{Acknowledgments}

Funding: Grants from Seoul National University (No. 800-20180373, 800-20190437, 800-20200309), the Korea Health Technology R\&D Project through the Korea Health Industry Development Institute (KHIDI) funded by the Ministry of Health \& Welfare (No. HI19C0664), and Korean Gynecologic Oncology Group (No. KGOGSNU-006) supported this study.

\section{Footnote}

Provenance and Peer Review: This article was commissioned by the Guest Editors (Sang Yoon Park, Jae Weon Kim) for the series "Ultra-Radical Surgery in Ovarian Cancer: Surgical Techniques for Gynecologic Oncologist" published in Gland Surgery. The article was sent for external peer review organized by the Guest Editors and the editorial office.

Conflicts of Interest: Both authors have completed the ICMJE uniform disclosure form (available at http://dx.doi. org/10.21037/gs-2019-ursoc-03). The series "UltraRadical Surgery in Ovarian Cancer: Surgical Techniques for Gynecologic Oncologist" was commissioned by the editorial office without any funding or sponsorship. HSK serves as an unpaid editorial board member of Gland Surgery from Aug 2019 to Jul 2021. The authors have other conflicts of interest to declare.

Ethical Statement: The authors are accountable for all aspects of the work in ensuring that questions related to the accuracy or integrity of any part of the work are appropriately investigated and resolved. This study was approved from the Institutional Review Board from Seoul National University College of Medicine \& Seoul National University Hospital (No. H-1812-021-991).

Open Access Statement: This is an Open Access article distributed in accordance with the Creative Commons Attribution-NonCommercial-NoDerivs 4.0 International License (CC BY-NC-ND 4.0), which permits the non- 
commercial replication and distribution of the article with the strict proviso that no changes or edits are made and the original work is properly cited (including links to both the formal publication through the relevant DOI and the license). See: https://creativecommons.org/licenses/by-nc-nd/4.0/.

\section{References}

1. Sugarbaker PH. Avoiding diverting ileostomy in patients requiring complete pelvic peritonectomy. Ann Surg Oncol 2016;23:1481-5.

2. Gallotta V, Fanfani F, Vizzielli G, et al. Douglas peritonectomy compared to recto-sigmoid resection in optimally cytoreduced advanced ovarian cancer patients: analysis of morbidity and oncological outcome. Eur J Surg Oncol 2011;37:1085-92.

3. Emmertsen KJ, Laurberg S. Low anterior resection syndrome score: development and validation of a symptom-based scoring system for bowel dysfunction after low anterior resection for rectal cancer. Ann Surg 2012;255:922-8.

4. Grimm C, Harter P, Alesina PF, et al. The impact of type and number of bowel resections on anastomotic leakage

Cite this article as: Park SJ, Kim HS. Surgical technique of visceral segmental serosectomy for advanced ovarian cancer. Gland Surg 2021;10(3):1276-1278. doi: 10.21037/gs-2019ursoc-03 risk in advanced ovarian cancer surgery. Gynecol Oncol 2017;146:498-503.

5. Kalogera E, Dowdy SC, Mariani A, et al. Multiple large bowel resections: potential risk factor for anastomotic leak. Gynecol Oncol 2013;130:213-8.

6. Aletti GD, Podratz KC, Jones MB, et al. Role of rectosigmoidectomy and stripping of pelvic peritoneum in outcomes of patients with advanced ovarian cancer. J Am Coll Surg 2006;203:521-6.

7. Park SJ, Kim J, Kim SN, et al. Practice patterns of surgery for advanced ovarian cancer: analysis from international surveys. Jpn J Clin Oncol 2019;49:137-45.

8. Shih KK, Chi DS. Maximal cytoreductive effort in epithelial ovarian cancer surgery. J Gynecol Oncol 2010;21:75-80.

9. Kim M, Suh DH, Park JY, et al. Survival impact of low anterior resection in patients with epithelial ovarian cancer grossly confined to the pelvic cavity: a Korean multicenter study. J Gynecol Oncol 2018;29:e60.

10. $\mathrm{Wu} Z$, van de Haar RC, Sparreboom CL, et al. Is the intraoperative air leak test effective in the prevention of colorectal anastomotic leakage? A systematic review and meta-analysis. Int J Colorectal Dis 2016;31:1409-17. 